\title{
Combined effects of global change pressures on animal-mediated pollination
}

\section{Juan P. González-Varo ${ }^{1}$, Jacobus C. Biesmeijer ${ }^{2}$, Riccardo Bommarco ${ }^{3}$, Simon G. Potts ${ }^{4}$, Oliver Schweiger ${ }^{5}$, Henrik G. Smith ${ }^{6}$, Ingolf Steffan-Dewenter ${ }^{7}$, Hajnalka Szentgyörgyi ${ }^{8}$, Michał Woyciechowski ${ }^{8}$, and Montserrat Vilà ${ }^{1}$}

\footnotetext{
${ }^{1}$ Estación Biológica de Doñana (EBD-CSIC), Avda. Américo Vespucio, s/n, Isla de la Cartuja, 41092 Sevilla, Spain

${ }^{2}$ Naturalis Biodiversity Center, PO Box 9517, 2300 RA Leiden, The Netherlands

${ }^{3}$ Swedish University of Agricultural Sciences, Department of Ecology, SE-75007 Uppsala, Sweden

${ }^{4}$ School of Agriculture, Policy, and Development, University of Reading, Reading, RG6 6AR, UK

${ }^{5}$ UFZ, Helmholtz Centre for Environmental Research (UFZ), Department of Community Ecology, Theodor-Lieser-Str. 4, 06120 Halle, Germany

${ }^{6}$ Department of Biology \& Centre of Environmental and Climate Research, Lund University, S-223 62 Lund, Sweden

${ }^{7}$ Department of Animal Ecology and Tropical Biology, Biocentre, University of Würzburg, Am Hubland, 97074 Würzburg, Germany

${ }^{8}$ Institute of Environmental Sciences, Jagiellonian University, Gronostajowa 7, 30-387 Krakow, Poland
}

Pollination is an essential process in the sexual reproduction of seed plants and a key ecosystem service to human welfare. Animal pollinators decline as a consequence of five major global change pressures: climate change, landscape alteration, agricultural intensification, non-native species, and spread of pathogens. These pressures, which differ in their biotic or abiotic nature and their spatiotemporal scales, can interact in nonadditive ways (synergistically or antagonistically), but are rarely considered together in studies of pollinator and/or pollination decline. Management actions aimed at buffering the impacts of a particular pressure could thereby prove ineffective if another pressure is present. Here, we focus on empirical evidence of the combined effects of global change pressures on pollination, highlighting gaps in current knowledge and future research needs.

\section{Animal-mediated pollination under global change}

Pollination is an essential process in the sexual reproduction of angiosperm species, more than 260000 of which (88\%) rely on animals for pollen transfer [1]. In turn, approximately 300000 animal species are attracted to visit angiosperm flowers by pollen and nectar rewards [2]. Besides the critical role of this mutualism for the maintenance of biodiversity, animal-mediated pollination also provides a key ecosystem service to society. Approximately $70 \%$ of the major crop species worldwide are at least partly reliant on animal pollination (mainly by insects) for yield production, accounting for 35\% of global food production [3].

Pollinator declines have been attributed to different global change pressures [4-7]. Climate change [8,9], landscape alteration [10,11], species invasions [12,13], agricultural

Corresponding author: González-Varo, J.P. (juanpe@ebd.csic.es). intensification [14-16], and spread of pathogens [17] have been identified as the main causes of declines in pollinator abundances and extinctions, with the latter causing shifts in pollinator community composition [18], disruption of plantpollinator interactions [19], and loss or destabilisation of pollination services to wild [19] and crop plants [10,20,21].

Terrestrial ecosystems are currently impacted by multiple pressures and, thus, knowledge of the interactive effects between them is essential for both biodiversity conservation and the maintenance of the ecosystem services provided by pollinators [22]. Indeed, the effects of one pressure can be amplified or buffered by the effects of another pressure $[22,23]$. The management implication of such interactive effects is that action plans aimed at buffering the effects of a particular pressure can become ineffective if another pressure is present, potentially resulting in a waste of resources devoted to mitigation (e.g., [24]).

In this paper, we focus on the empirical evidence of combined effects of multiple global change pressures on animal-mediated pollination, and discuss both the consequences for pollination services and the potential implications for management. We draw attention to the spatiotemporal scales of impact, the experimental approaches used to study them, the gaps in current knowledge, and future research needs.

From single effects of global change pressures to interactions between them

Single global change pressures have characteristic spatiotemporal scales of action and generate impacts at different rates and at different levels of ecological organisation, from individuals to ecosystems (Boxes 1 and 2). It is important to consider the contrasting biotic or abiotic nature of these pressures to understand their interactive impacts on animal-mediated pollination; environmental pressures can shape the distribution of species, but the presence of 


\section{Box 1. The global change pressures and their spatiotemporal scales of action}

\section{Climate change}

Climate change, mostly warming, typically occurs at broad spatial and temporal scales. However, increased climatic variability can result in climatically anomalous seasons and/or years at a regional scale, whereas anomalous weather events can occur locally during a short time period. Climate change entails changes in community composition through shifts in the geographical range and/or phenology of species.

\section{Landscape alteration}

Landscape alteration comprises the degradation (including diffuse pollution), destruction, and fragmentation of natural habitats, resulting in associated changes in landscape configuration, habitat diversity, and community composition. Although landscape alteration occurs at local and landscape scales, shared environment (e.g. orography) and policies can lead to similar alteration regimes at broader spatiotemporal scales.

\section{Agricultural intensification}

Intensive agriculture is characterised by an increase in input of pesticides and fertilisers, farm size, monocultures, and simplified crop rotations. Agricultural intensification and landscape alteration are usually difficult to separate because the highest levels of intensification generally occur in the most altered landscapes. Thus, agricultural intensification shares similar spatiotemporal scales with landscape alteration, but also comprises processes (e.g., ploughing and herbicide and/or pesticide application) that occur at the narrowest scales (plots and days).

\section{Invasive species}

The effects of biological invasions on animal-mediated pollination have usually been addressed considering non-native plants and nonnative pollinators (but see [12] for a study considering an invasive predator). Whereas non-native plants can require long lag-times until significant representation in the wild, non-native managed pollinators (mainly honeybees Apis mellifera and bumblebees Bombus spp.) can achieve huge abundances at short spatiotemporal scales after the introduction of hives.

\section{Pathogens}

The huge increase during the past decades in the trade of managed pollinators has promoted pathogen transmission to wild pollinators, and vice versa. Pathogen transmission occurs at landscape scales and during the first weeks after the release of managed hives. However, large-scale trends in the use of managed pollinators can lead to widespread transmission across a region.

\section{Box 2. Main documented impacts of single global change pressures on animal-mediated pollination}

\section{Climate change}

Climate change is predicted to cause spatial and temporal mismatches between pollinators and their food plants owing to differential shifts in the distribution ranges and phenology of interacting species, respectively $([8,9,23]$, but see [61]). Mismatches can cause pollen limitation to plants and gaps in food supply to pollinators, and both processes are expected to be particularly detrimental in specialist species [8]. Overall, the more generalist the relations (i.e., multiple pollinator species for a plant or broad diet in pollinators), the more resilient the interactions are under climate change. Consequently, non-random novel communities overrepresented by generalist species are expected after the spatial and phenological shifts of species distributions imposed by climate change $[8,23]$.

\section{Landscape alteration}

Landscape alteration generally involves the reduction of floral and nesting resources, isolation of populations, and shifts of biotic interactions. Landscape alteration results in significant reductions in species richness and abundance of pollinators, particularly of habitatand food-specialist insect taxa that locate their nests above ground $[11,62]$. As a consequence, habitat fragmentation produces strong negative effects on plant pollination and fecundity [63]. The compatibility system of plants, which reflects the degree of dependence on pollinator mutualism, explains the differences among species in their response to fragmentation [63].

\section{Agricultural intensification}

Agricultural intensification is thought to be a major driver of loss of pollinators $[14,15,24]$ and, thus, of pollination services [21]. Mechanical and chemical (herbicides) practices result in the loss of field margins and weeds that provide nest sites and forage resources for pollinators. Pesticides can directly affect the fitness of pollinators, leading to declines, particularly of wild species $[6,27,64]$. Increased use of inorganic fertilisers might also result in pollinator losses via

species cannot (normally) change the magnitude of the environmental changes.

A given pressure can impact animal-mediated pollination directly by disrupting the occurrence, abundance and phenology of partner species. However, a pressure can also impact pollination indirectly, by interacting with other pressures, either additively or nonadditively. Nonadditive homogenisation of floral communities [65].

\section{Invasive species}

Many non-native plants are ornamental entomophilous plants with floral displays attractive to native pollinators. These non-native plants integrate well within local pollination networks, receiving on average more pollinator visits than coexisting native plant species and, thus, acting as super-generalists $[30,34]$. Competition with native plants seems to prevail over facilitation [66], although the sign and magnitude of such effects are likely density dependent. Non-native pollinators can change the composition of local pollinator assemblages as a result of their high abundance [38] and their direct competition with native pollinators. Furthermore, non-native pollinators can disrupt pollination patterns of native plants [66]. Managed honeybees can reduce both fecundity and progeny performance through pollen limitation and inbreeding depression [37-39]. Some short-tongue bumblebees (e.g., Bombus terrestris) can bite a hole in the corolla of long-tube flowers [20,31], which can also be used by subsequent visitors, leading to illegitimate visits and reduction of plant fitness.

\section{Pathogens}

Pathogen transmission from managed to wild pollinators, and vice versa, has resulted in widespread pollinator declines $[6,17]$. The bestknown cases are the transmissions (mainly the Varroa mite and intestinal protozoans Nosema spp. and Crithidia spp.) between native Asiatic honeybee (Apis cerana) and non-native and managed European honeybees (Apis mellifera; $[6,67]$ ), and between managed (mainly originating from Europe) and wild bumblebees $[40,41,44,58]$. Although some of these pathogens can be transferred between phylogenetically more distant species (e.g., bumblebees and honeybee), there is a lack of studies on infection of wild pollinators not belonging to the Apis or Bombus genera. Transfer of RNA viruses has also been found among honeybees, bumblebees, and other non-Apis taxa of wild bees [43].

effects occur if the effect of a given pressure is amplified or buffered when it occurs in combination with another pressure. Many interactive effects are indirect effects in which a pressure modifies the magnitude (quantity) of another pressure (i.e., interaction chain effects) and/or its impact per capita (quality; i.e., interaction modification effects [22]). Indirect effects are expected to be particularly 
In the real world, animal-mediated pollination is impacted by more than one pair of global change pressures, so that multi-pressure complex interactive effects are probably the norm rather than the exception [23,52]. Figure I represents the possible combined negative effects of three pressures on native bumblebees and their pollination services: landscape alteration, invasion by a non-native bumblebee, and spread of non-native pathogens (based on $[17,20,31,40,41,58])$. Landscape alteration might impact native bumblebees directly by reducing floral and nesting resources. Indirect impacts include: (i) 'interaction chain effects' favouring the abundance of the non-native bumblebee; and (ii) 'interaction modification effects' increasing its per capita impact through resource limitation, which additionally would increase the probability of pathogen spillover [22]. Cascading effects on plant pollination are expected if the non-native bumblebee is less efficient than the native pollinator or if it visits flowers illegitimately, for example by nectar robbing [31]. Nectar robbing is expected to be more frequent in the commercially traded bumblebee Bombus terrestris owing to its shorter tongue length compared with other bumblebee species $[20,31]$.

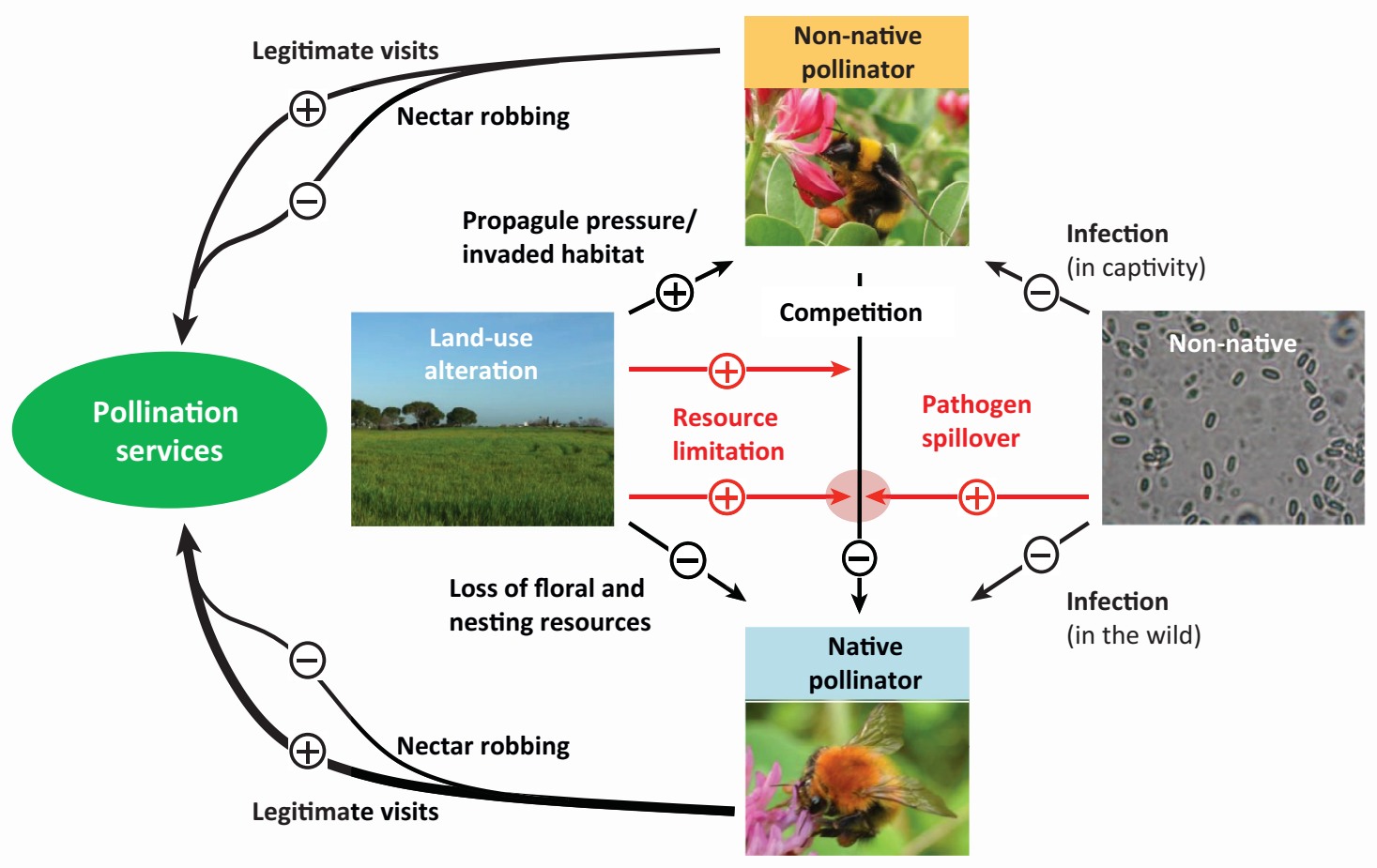

$\overline{T R E N D S ~ i n ~ E c o l o g y ~ \& ~ E v o l u t i o n ~}$

Figure I. Scheme showing possible synergistic effects between landscape alteration, invasion by a non-native pollinator, and pathogen spread impacting native pollinators and their pollination services. Black arrows represent direct effects, whereas red arrows represent (indirect) interactive effects by which a pressure (landscape alteration or pathogens) change the per capita impact of the non-native pollinator on the native pollinator [22]. Positive or negative signs in the arrows denote an increase or a decrease, respectively, in the variable of study, whereas the text close to each arrow denotes the mechanism(s) responsible for its effects. The shaded ellipse denotes a higher probability of pathogen spillover due to flower resource limitation in altered landscapes. The pollination services provided by both pollinators will depend on whether they perform legitimate visits or nectar robbing. Photo reproduced with permission from A. Montero-Castaño (top), H. Szentgyorgyi (right), and J.P. González-Varo (bottom and left).

common in interactions between environmental (climate change, landscape alteration, or agricultural intensification) and biotic pressures (such as invasion of non-native species, or spread of pathogens), because the former can potentially affect both the abundance and the per capita impact of the latter (Box 3, Figure I).

Only a few empirical studies have explicitly explored the interactive effects of multiple global change pressures on pollinators and pollination (Table 1). In the following sections, we summarise studies focusing on the paired combinations of these pressures, aiming to identify gaps in current knowledge and priorities for future research.

\section{Landscape alteration and agricultural intensification}

The interactive effect between agricultural intensification and landscape alteration is the most commonly assessed interaction, largely motivated by evaluations of the context dependent effects of agri-environmental schemes on biodiversity (Table 1). A common experimental approach is a factorial design with two levels within each factor. Levels for landscape alteration are usually 'simple versus complex', 'homogeneous versus heterogeneous' [25] or 'close to versus far from' edges of semi-natural habitats [26], whereas levels for agricultural intensification usually are 'conventional versus organic' farming, although some studies have compared farms with and without pesticide application [27].

In general, the negative effects of agricultural intensification on pollinator species richness and abundance are stronger in simple (i.e., low cover of semi-natural habitats) than in complex landscapes, indicating synergistic effects between both pressures [24]. A plausible explanation is that farms in complex landscapes are more likely to have higher pollinator diversity than are those in simple landscapes. Therefore, the effects of organic farming are weak in the former and stronger in the latter [24]. Although most 


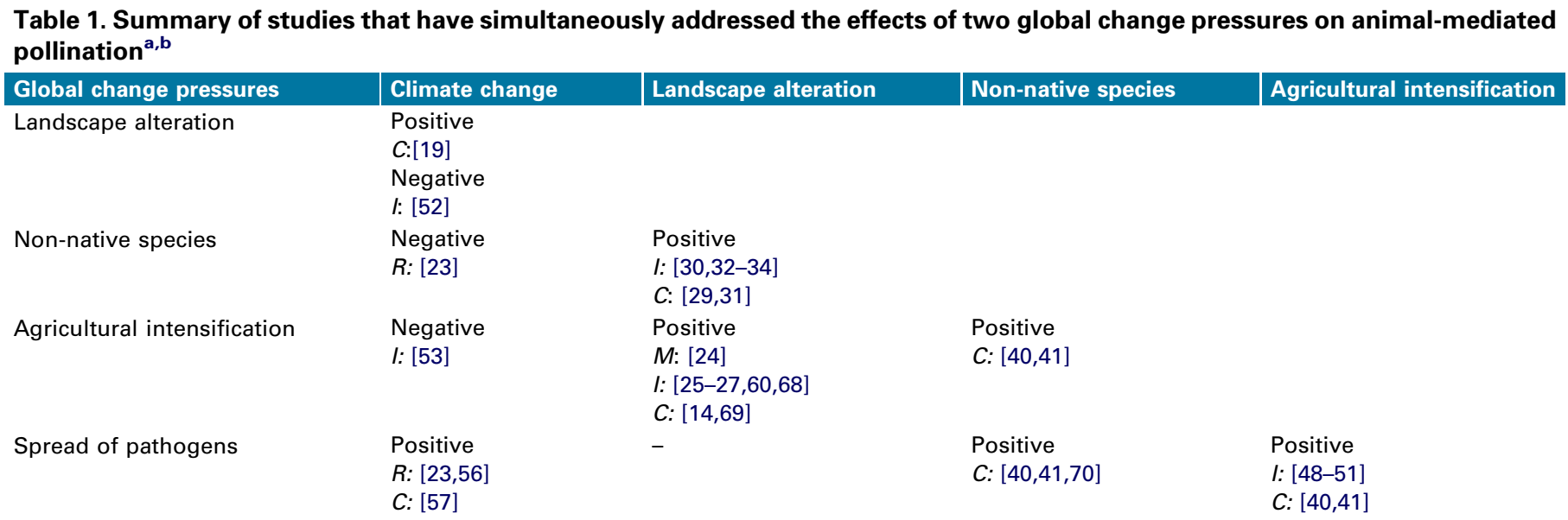

a'Positive' and 'Negative' denote the type of combined effect between pairs of pressures on diverse response variables related to pollinators (assemblages, species, populations, and individual fitness) and/or pollination-associated processes (visitation rates, pollen limitation, mating patterns, and fecundity).

b $/$, studies that explicitly tested for interactive effects between pressures; $C$, studies that assessed simultaneously the effects of two pressures but not the interaction; $R$, review studies; $M$, meta-analytical studies.

studies have only focused on pollinators, changes in their abundance and composition are expected to have consequences on the magnitude and stability of the pollination service needed for fruit and seed production of wild plants $[19,28]$ and agricultural crops [10,14,21]. The implication for management of this relatively well-studied interactive effect is that certain policy actions aimed at buffering the negative effects of agricultural intensification can be more efficient in moderate to highly altered landscapes compared with little altered landscapes [24].

\section{Landscape alteration and non-native species}

Several studies have considered the effect of landscape type in combination with the occurrence of non-native pollinators or plants (Table 1). In these studies, the degree of landscape alteration has been accounted for either categorically; for example, 'continuous versus fragmented' or 'disturbed versus undisturbed' [29,30], or continuously along a gradient of landscape naturalness [31,32]. Invasion is assessed at the local plot level ('invaded versus noninvaded'). In general, both non-native plants and pollinators are disproportionally more abundant in highly altered landscapes, such as in disturbed habitats, or in small remnant patches of semi-natural habitat [29,31,33,34]. Thus, it is difficult to disentangle the causal effects of landscape alteration from those of invasion.

With regard to non-native pollinators, only a few case studies exist. Ishii et al. [31] studied the distribution of nonnative (Bombus terrestris) and native (Bombus spp.) bumblebees as well as their foraging behaviour visiting flowers along transitions from open farmland habitats to forests in central Hokkaido, Japan. They found that B. terrestris occupied deforested areas, where they had displaced native Bombus spp. to forest habitats, which seem to act as barriers against the expansion of $B$. terrestris. Given that B.terrestris is a short-tongued pollinator, the consequence for many plants is an increase in nectar robbing (i.e., illegitimate visits performed by biting a hole in the corolla tube) on long-tube flowers in the most deforested landscapes. In another study, Dick et al. [29] examined the mating patterns and pollen dispersal distances of Dinizia excelsa trees in fragmented versus continuous rainforests in Brazil. Whereas flower visits in continuous forests were performed almost exclusively by native pollinators, introduced honeybees were the main flower visitor on remnant $D$. excelsa trees located in pastures. For this self-incompatible tree, honeybees provide genetic rescue by promoting long-distance mating events that connect continuous and fragmented populations. Managed honeybees can also reduce pollen limitation of self-compatible plants through high flower visitation rates [35]. Nevertheless, because they tend to forage on many flowers of the same individual plant [36], honeybees usually promote geitonogamous crossings, particularly in those that bear large numbers of flowers [35,37], which can reduce fecundity [38] and plant progeny performance through self-incompatibility and/or inbreeding depression [39].

With regard to non-native plants, Williams et al. [33] studied bee visits to non-native and native plants in transformed and semi-natural habitats of California and New Jersey (USA). They found a positive interaction between landscape alteration and non-native plants on beeplant interactions; bee visits (species richness and abundance) to non-native plants were greater in transformed than in semi-natural habitats. However, bees foraged on different flower species according to their local abundance, denoting a lack of preference for non-native flowers.

Additionally, non-native pollinators and plants can form 'invader complexes'; that is, groups of introduced species interacting more with each other than expected by chance, which might have positive feedbacks facilitating the invasion of undisturbed habitats [34]. For example, in temperate forests of the southern Andes, non-native visitors, mainly Apis mellifera and Bombus ruderatus, visited flowers of non-native plants more frequently in disturbed than in undisturbed habitats; however, there was no interaction between habitat disturbance and plant origin (native or non-native) [34]. As in the case of Williams et al. [33], this result could be explained by the greater abundance of non-native plants in disturbed habitats. 


\section{Pathogens and non-native species}

The interactive effects of non-native species and pathogen transmission have been examined in terms of pathogen spillover from commercially reared honeybees and bumblebees to wild pollinators. In a case study in southern Ontario (Canada), three bumblebee pathogens (two microsporidia and a tracheal mite) infected native bumblebees via shared flowers more frequently in landscapes with greenhouses than in those lacking them [40]. A follow-up study found a sharp decline in infection rates by the microsporidian Crithidia bombi in wild bumblebees with distance from greenhouses with commercial bumblebee hives (Bombus impatiens) [41]. In addition, the most infected wild bumblebee species were those with a high similarity with the commercial bumblebee in the use of plant species. Pathogen spillover to wild bee taxa not belonging to the genera Apis and Bombus is likely to also be important $[42,43]$, and there is a huge knowledge gap on this issue [44].

\section{Pathogens and landscape alteration or agricultural intensification}

The impact of pathogens on pollinators is expected to be higher in altered and intensively cultivated landscapes, where pollinator nutrition and, thus, health (immune system [45]), relies on poor flower communities. This positive interaction is supported by significant correlations between the honeybee colony loss suffered by the states in the USA and the extent of their main land-use types [46].

Although the combined effects of pathogen spread and landscape alteration have not been assessed directly so far (Table 1), available evidence suggests that pathogen spillover from commercial pollinators should be much greater (positive interaction) in altered landscapes, where floral resources are usually scarcer and mean foraging distances are larger (e.g., [31,40,41,47]) (Box 3 , Figure I). Similarly, a positive interactive effect is also expected between pathogen spillover and agricultural intensification, because both insecticides and pathogens have detrimental effects on the health of wild pollinators. Indeed, Pettis et al. [48] recently found that microsporidia infections (Nosema sp.) increased significantly in honeybees exposed to a widely used pesticide; thus, the authors demonstrated experimentally an indirect positive effect of pesticides on pathogen spread. Moreover, several tests on joint effects between infection by a microsporidian (Nosema ceranae) and exposure to a neonicotinoid insecticide on honeybee performance, show that several fitness parameters decreased only by the combination of both factors [49-51]. These results provide strong evidence of synergistic effects between pathogen infection and pesticide use. As noted, agricultural intensification is typically associated with the presence of managed, and often non-native, pollinators used to provide pollination services to intensively produced crops (e.g., [14,21,40]). There is, however, a lack of studies assessing whether native pollinators are more impacted by such synergistic effects than the nonnatives.
Climate change and landscape alteration or agricultural intensification

Landscape alteration and climate change are expected to affect animal-mediated pollination synergistically, causing spatiotemporal mismatches between interacting species [19] (Box 2). Only one study has experimentally assessed the interactive effect of climate change and landscape alteration on animal-mediated pollination [52]. Pollinator visits and seed production were examined in experimental patches of native flowers. Pots with wild mustard (Sinapsis arvensis) grown with 'normal' and 'advanced' flowering phenology were placed both 'close' and 'distant' to seminatural grasslands. Advanced flowering simulated a phenological shift in flowering due to global warming, and distance to grasslands represented landscape alteration. A negative interaction between flowering phenology and proximity to grasslands was found: the difference in the number of flower visits by wild bees to 'distant' $(>500 \mathrm{~m})$ and 'close' $(0 \mathrm{~m})$ flower islands was higher under normal than under advanced flowering phenology. This result could be explained by more similar local flower abundance between close and distant experimental islands in the advanced phenology scenario as compared with the normal one.

Recently, Hoover et al. [53] examined interactive effects between warming, increased $\mathrm{CO}_{2}$ and nitrogen $(\mathrm{N})$ deposition in laboratory trials on several plant and flower traits of pumpkin (Cucurbita maxima) as well as on domestic bumblebee (B. terrestris) foraging preferences and longevity. To our knowledge, this is the only study that has examined interactive effects between climate change and agricultural intensification, because $\mathrm{N}$ deposition can be linked to agricultural intensification [54]. There was an antagonistic effect between warming and $\mathrm{N}$ deposition in that both nectar production (by plants) and nectar consumption (by bumblebees) in the $\mathrm{N}$-enriched treatment were higher under normal than under elevated temperatures. Although such experiments are valuable because they provide insights into the mechanisms underlying plant and pollinator responses, they often represent an oversimplification of the real world. For example, the studies by Parsche et al. [52] and Hoover et al. [53] considered climate change effects (phenological shifts and alterations in nectar composition, respectively) in a single plant species. However, climate change tends to impact on entire communities, which means that generalisations based on microcosm studies should be made with caution [23].

\section{Climate change and non-native species or pathogens}

There is a lack of empirical studies testing interactive effects of climate change and non-native species on animal-mediated pollination. Schweiger et al. [23] compiled literature concerning both global change pressures and developed hypotheses about their possible interactive effects. The authors hypothesised that atypical flowering phenology of non-native species might buffer (antagonistic effect) the detrimental effects of temporal mismatches between interacting species caused by climate change [8]. In temperate regions, many non-native plants are from warmer areas and exhibit a high tolerance to a wide range of climatic conditions; therefore, they have the potential to fill gaps and curtailments in food supply to native 
pollinators [8]. In support of this hypothesis, Stelzer and collaborators [55] recently observed that ornamental plant species of urban areas in southern England provide food to bumblebees (B. terrestris) that are increasingly active during warmer winters. In addition, features of non-native pollinators, mainly A. mellifera and Bombus spp., such as sociality, long foraging seasons, broad diets, and long flight ranges, might buffer spatiotemporal mismatches between flowering plants and their native partners.

There is also potential for a positive interactive effect between climate change and pathogen virulence, because there could be changes in the geographical distribution and severity of those diseases whose pathogens respond positively to expected climatic changes [23,56]. In fact, MartínHernández et al. [57] found that $N$. ceranae (the microsporidian intestinal parasite of the Asiatic honeybee Apis cerana that has been transferred to the European honeybee A. mellifera worldwide) can develop at a wider temperature range than its congener Nosema apis and lacks epidemiological seasonality.

\section{Concluding remarks and future directions}

Despite advances in understanding the single effects of global change pressures on animal-mediated pollination, studies simultaneously considering multiple pressures are scarce (Table 1), highlighting that knowledge is still limited. Overall, there is evidence of synergistic effects between agricultural intensification and landscape alteration affecting pollinators negatively. In the case of synergistic effects, the reduction of one pressure will ultimately lead to the reduction in the combined effect. Accordingly, the positive effects of organic farming on pollinators can be negligible in complex or well-preserved landscapes but highly beneficial in simple or highly altered landscapes. Similarly, conserving and restoring (semi-) natural habitats and increasing landscape heterogeneity can be beneficial within intensive croplands. Synergistic effects also occur between agricultural intensification and pathogen virulence, demonstrating that both infection rates and damage caused by pathogens are higher in pollinators exposed to pesticides. In addition, infection rates are higher in landscapes with intensive cropping systems that typically use commercial beehives for pollination. Taken together, such positive interactions, either synergistic or additive, are evidence of multi-pressure effects being common mechanisms underlying the declines of both pollinators and pollination services (Box 3).

That said, many interactions are still unexplored (Table 1). For example, given that pathogen spillover is considered a major driver for observed bumblebee declines in North America [17,44,58], more attention should be paid to pathogen spread under contrasting scenarios of landscape alteration. Also unexplored are interactions between climate change and landscape alteration, agricultural intensification, or non-native species. Climate change is expected to cause phenological mismatches in the poor plant-pollinator communities of altered and intensively cultivated landscapes, jeopardising both plant reproduction and pollinator feeding. However, non-native plants and pollinators could provide food and pollination function, respectively, to native partners in periods where native plants and pollinators have curtailed their phenology. In the case of this potentially, and unexplored, antagonistic interaction between climate change and non-native species, the reduction of one pressure will lead to an increase in the severity of the other pressure (even if this pressure is held constant).

In summary, the outstanding challenges are to combine observational and manipulative experimental designs to analyse explicitly pair-wise, and further multiple (Box 3), interactions between pressures [59]. For this purpose, it is important to consider the spatiotemporal scales of action of the pressures as well as their hierarchical differences for the combined effects. As mentioned above, environmental pressures can potentially shape the distribution of species (and their per capita impact; Box 3), but the spread of species cannot shape the magnitude of the environmental changes. With such approaches, we will be able to understand the sign and magnitude of multi-pressure effects, which are essential to guide the most appropriate mitigation and adaptation options to conserve plant and pollinator biodiversity and, ultimately, to manage pollination services.

\section{Acknowledgements}

We thank comments from two anonymous referees on an early version of the manuscript. This review was prepared with support from the STEP Project (Status and Trends of European Pollinators, http://www.stepproject.net, EU 7th Framework Program, grant 244090 [59]) and the Ministerio de Ciencia e Innovación projects RIXFUTUR (CGL200907515) and MONTES (CSD2008-00040).

\section{References}

1 Ollerton, J. et al. (2011) How many flowering plants are pollinated by animals? Oikos 120, 321-326

2 Kearns, C.A. et al. (1998) Endangered mutualisms: the conservation of plant-pollinator interactions. Annu. Rev. Ecol. Evol. Syst. 29, 83-112

3 Klein, A.M. et al. (2007) Importance of pollinators in changing landscapes for world crops. Proc. R. Soc. Lond. B 274, 303-313

4 Biesmeijer, J.C. et al. (2006) Parallel declines in pollinators and insectpollinated plants in Britain and the Netherlands. Science 313, 351-354

5 Brown, M.J.F. and Paxton, R.J. (2009) The conservation of bees: a global perspective. Apidologie 40, 410-416

6 Potts, S.G. et al. (2010) Global pollinator declines: trends, impacts and drivers. Trends Ecol. Evol. 25, 345-353

7 Winfree, R. (2010) The conservation and restoration of wild bees. Ann. N. Y. Acad. Sci. 1195, 169-197

8 Memmott, J. et al. (2007) Global warming and the disruption of plantpollinator interactions. Ecol. Lett. 10, 710-717

9 Hegland, S.J. et al. (2009) How does climate warming affect plantpollinator interactions? Ecol. Lett. 12, 184-195

10 Garibaldi, L.A. et al. (2011) Stability of pollination services decreases with isolation from natural areas despite honey bee visits. Ecol. Lett. $14,1062-1072$

11 Winfree, R. et al. (2011) Native pollinators in anthropogenic habitats. Annu. Rev. Ecol. Evol. Syst. 42, 1-22

12 Abe, T. et al. (2008) Why have endemic pollinators declined on the Ogasawara Islands? Biodivers. Conserv. 17, 1465-1473

13 Moron, D. et al. (2009) Wild pollinator communities are negatively affected by invasion of alien goldenrods in grassland landscapes. Biol. Conserv. 142, 1322-1332

14 Kremen, C. et al. (2002) Crop pollination from native bees at risk from agricultural intensification. Proc. Natl. Acad. Sci. U.S.A. 99, 16812-16816

15 Tscharntke, T. et al. (2005) Landscape perspectives on agricultural intensification and biodiversity: ecosystem service management. Ecol. Lett. 8, 857-874

16 Whitehorn, P.R. et al. (2012) Neonicotinoid pesticide reduces bumble bee colony growth and queen production. Science 336, 351-352

17 Cameron, S.A. et al. (2011) Patterns of widespread decline in North American bumble bees. Proc. Natl. Acad. Sci. U.S.A. 108, 662-667

18 Bartomeus, I. et al. (2013) Historical changes in northeastern US bee pollinators related to shared ecological traits. Proc. Natl. Acad. Sci. U.S.A. http://dx.doi.org/10.1073/pnas.1218503110 
19 Burkle, L.A. et al. (2013) Plant-pollinator interactions over 120 years: loss of species, co-occurrence and function. Science http://dx.doi.org/ $10.1126 /$ science. 1232728

20 Bommarco, R. et al. (2012) Drastic historic shifts in bumble bee community composition in Sweden. Proc. R. Soc. Lond. B 279, 309-315

21 Garibaldi, L.A. et al. (2013) Wild pollinators enhance fruit set of crops regardless of honey bee abundance. Science http://dx.doi.org/10.1126/ science. 1230200

22 Didham, R.K. et al. (2007) Interactive effects of habitat modification and species invasion on native species decline. Trends Ecol. Evol. 22, 489-496

23 Schweiger, O. et al. (2010) Multiple stressors on biotic interactions: how climate change and alien species interact to affect pollination. Biol. Rev. 85, 777-795

24 Batáry, P. et al. (2011) Landscape-moderated biodiversity effects of agri-environmental management: a meta-analysis. Proc. R. Soc. Lond. B 278, 1894-1902

25 Rundlöf, M. and Smith, H.G. (2006) The effect of organic farming on butterfly diversity depends on landscape context. J. Appl. Ecol. 43, 1121-1127

26 Pe'er, G. et al. (2011) Butterfly diversity at the ecotone between agricultural and semi-natural habitats across a climatic gradient. Divers. Distrib. 17, 1186-1197

27 Otieno, M. et al. (2011) Local management and landscape drivers of pollination and biological control services in a Kenyan agro-ecosystem. Biol. Conserv. 144, 2424-2431

28 Steffan-Dewenter, I. et al. (2001) Pollination, seed set and seed predation on a landscape scale. Proc. R. Soc. Lond. B: Biol. Sci. 268, $1685-1690$

29 Dick, C.W. et al. (2003) Pollen dispersal of tropical trees (Dinizia excelsa: Fabaceae) by native insects and African honeybees in pristine and fragmented Amazonian rainforest. Mol. Ecol. 12, 753-764

30 Aizen, M.A. et al. (2008) Invasive mutualists erode native pollination webs. PLoS Biol. 6, e31

31 Ishii, H. et al. (2008) Habitat and flower resource partitioning by an exotic and three native bumble bees in central Hokkaido, Japan. Biol. Conserv. 141, 2597-2607

32 Bartomeus, I. et al. (2010) Combined effects of Impatiens glandulifera invasion and landscape structure on native plant pollination. J. Ecol. 98, 440-450

33 Williams, N.M. et al. (2011) Bees in disturbed habitats use, but do not prefer, alien plants. Basic Appl. Ecol. 12, 332-341

34 Morales, C. and Aizen, M.A. (2002) Does invasion of exotic plants promote invasion of exotic flower visitors? A case study from the temperate forests of the southern Andes. Biol. Invas. 4, 87-100

35 González-Varo, J.P. et al. (2009) Effects of fragmentation on pollinator assemblage, pollen limitation and seed production of Mediterranean myrtle (Myrtus communis). Biol. Conserv. 142, 1058-1065

36 Goulson, D. (2003) Effects of introduced bees on native ecosystems. Annu. Rev. Ecol. Evol. Syst. 34, 1-26

37 England, P. et al. (2001) A molecular genetic assessment of mating-system variation in a naturally bird-pollinated shrub: contributions from birds and introduced honeybees. Conserv. Biol. $15,1645-1655$

38 Valido, A. et al. (2011) Interacciones entre plantas y polinizadores en el Parque Nacional del Teide: consecuencias ecológicas de la introducción masiva de la abeja doméstica (Apis mellifera, Apidae). In Proyectos de investigacion en Parques Nacionales (MMARM ed), pp. 205-231, MARM

39 González-Varo, J.P. et al. (2010) Linking genetic diversity, mating patterns and progeny performance in fragmented populations of a Mediterranean shrub. J. Appl. Ecol. 47, 1242-1252

40 Colla, S.R. et al. (2006) Plight of the bumble bee: pathogen spillover from commercial to wild populations. Biol. Conserv. 129, 461-467

41 Otterstatter, M.C. and Thomson, J.D. (2008) Does pathogen spillover from commercially reared bumble bees threaten wild pollinators? PLoS ONE 3, e2771

42 Evison, S.E.F. et al. (2012) Pervasiveness of parasites in pollinators. PLoS ONE 7, e30641

43 Singh, R. et al. (2010) RNA viruses in hymenopteran pollinators: evidence of inter-taxa virus transmission via pollen and potential impact on non-Apis hymenopteran species. PLOS ONE 5, e14357
44 Meeus, I. et al. (2011) Effects of invasive parasites on bumble bee declines. Conserv. Biol. 25, 662-671

45 Alaux, C. et al. (2010) Diet effects on honeybee immunocompetence. Biol. Lett. 6, 562-565

46 Naug, D. (2009) Nutritional stress due to habitat loss can explain recent honeybee colony collapses. Biol. Conserv. 142, 2369-2372

47 Steffan-Dewenter, I. and Kuhn, A. (2003) Honeybee foraging in differentially structured landscapes. Proc. R. Soc. Lond. B 270, 569-575

48 Pettis, J.S. et al. (2012) Pesticide exposure in honey bees results in increased levels of the gut pathogen Nosema. Naturwissenschaften 99, 153-158

49 Alaux, C. et al. (2010) Interactions between Nosema microspores and a neonicotinoid weaken honeybees (Apis mellifera). Environ. Microbiol. $12,774-782$

50 Vidau, C. et al. (2011) Exposure to sublethal doses of fipronil and thiacloprid highly increases mortality of honeybees previously infected by Nosema ceranae. PLoS ONE 6, e21550

51 Aufauvre, J. et al. (2012) Parasite-insecticide interactions: a case study of Nosema ceranae and fipronil synergy on honeybee. Sci. Rep. 2, 326

52 Parsche, S. et al. (2011) Experimental environmental change and mutualistic vs. antagonistic plant flower-visitor interactions. Perspect. Plant Ecol. Evol. Syst. 13, 27-35

53 Hoover, S.E.R. et al. (2012) Warming, $\mathrm{CO}_{2}$, and nitrogen deposition interactively affect a plant-pollinator mutualism. Ecol. Lett. 15, 227-234

54 Bobbink, R. et al. (2010) Global assessment of nitrogen deposition effects on terrestrial plant diversity: a synthesis. Ecol. Appl. 20,30-59

55 Stelzer, R.J. et al. (2010) Winter active bumblebees (Bombus terrestris) achieve high foraging rates in urban Britain. PLoS ONE 5, e9559

56 Le Conte, Y. and Navajas, M. (2008) Climate change: impact on honey bee populations and diseases. Rev. Sci. Tech. Off. Int. Epizoot. 27, 499-510

57 Martín-Hernández, R. et al. (2009) Effect of temperature on the biotic potential of honeybee microsporidia. Appl. Environ. Microbiol. 75, $2554-2557$

58 Szabo, N.D. et al. (2012) Do pathogen spillover, pesticide use, or habitat loss explain recent North American bumblebee declines? Conserv. Lett. $5,232-239$

59 Potts, S.G. et al. (2011) Developing European conservation and mitigation tools for pollination services: approaches of the STEP (Status and Trends of European Pollinators) project. J. Apic. Res. $50,152-164$

60 Rundlöf, M. et al. (2008) Interacting effects of farming practice and landscape context on bumblebees. Biol. Conserv. 141, 417-426

61 Bartomeus, I. et al. (2011) Climate-associated phenological advances in bee pollinators and bee-pollinated plants. Proc. Natl. Acad. Sci. U.S.A. 108, 20645-20649

62 Williams, N.M. et al. (2010) Ecological and life-history traits predict bee species responses to environmental disturbances. Biol. Conserv. $143,2280-2291$

63 Aguilar, R. et al. (2006) Plant reproductive susceptibility to habitat fragmentation: review and synthesis through a metaanalysis. Ecol. Lett. 9, 968-980

64 Gill, R.J. et al. (2012) Combined pesticide exposure severely affects individual- and colony-level traits in bees. Nature http://dx.doi.org/ 10.1038/nature 11585

65 Wesche, K. et al. (2012) Fifty years of change in Central European grassland vegetation: large losses in species richness and animalpollinated plants. Biol. Conserv. 150, 76-85

66 Montero-Castaño, A. and Vilà, M. (2012) Impact of landscape alteration and invasions on pollinators: a meta-analysis. J. Ecol. $100,884-893$

67 Neumann, P. and Carreck, N.L. (2010) Honey bee colony losses. J. Apic. Res. 49, 1-6

68 Schweiger, O. et al. (2007) Functional richness of local hoverfly communities (Diptera, Syrphidae) in response to land use across temperate Europe. Oikos 116, 461-472

69 Le Féon, V. et al. (2010) Intensification of agriculture, landscape composition and wild bee communities: a large scale study in four European countries. Agric. Ecosyst. Environ. 137, 143-150

70 Kojima, Y. et al. (2011) Infestation of Japanese native honey bees by tracheal mite and virus from non-native European honey bees in Japan. Microb. Ecol. 62, 895-906 